\title{
REVIEWS
}

\section{An Estimate of the US Rate of Overuse of Screening Colonoscopy: a Systematic Review}

\author{
Joseph Fraiman, MD ${ }^{1,2}$ (D), Shannon Brownlee, $\mathrm{MSc}^{3}$, Michael A. Stoto, PhD ${ }^{4}$, \\ Kenneth W. Lin, MD, MPH ${ }^{5}$, and Alison N. Huffstetler, MD ${ }^{6}$
}

\begin{abstract}
'Department of Emergency Medicine, Thibodaux Regional Medical Center, Thibodaux, LA, USA; ${ }^{2}$ New Orleans, USA; ${ }^{3}$ Lown Institute, Boston, MA, USA; ${ }^{4}$ Department of Health Systems Administration, Georgetown University, Washington, DC, USA; ${ }^{5}$ Department of Family Medicine, Georgetown University School of Medicine, Washington, DC, USA; ${ }^{6}$ Virginia Commonwealth University, Richmond, VA, USA.
\end{abstract}

BACKGROUND: This study aims to assess the rate at which screening colonoscopy is performed on patients younger or older than the age range specified in national guidelines, or at shorter intervals than recommended. Such non-indicated use of the procedure is considered low-value care, or overuse. This study is the first systematic review of the rate of non-indicated completed screening colonoscopy in the USA.

METHODS: PubMed and Embase were queried for relevant studies on overuse of screening colonoscopy published from January 1, 2002, until January 23, 2019. English-language studies that were conducted for screening colonoscopy after 2001 for average-risk patients were included. Studies must have followed national guidelines for detecting rates of overuse. We followed methods outlined in the Preferred Reporting Items for Systematic Reviews and Meta-Analyses (PRISMA) and the reporting recommendations of the Meta-analysis of Observational Studies in Epidemiology group (MOOSE).

RESULTS: A total of 772 papers were reviewed for inclusion; 42 were reviewed in full text. Of those reviewed, six studies met eligibility criteria, including a total of 459,503 colonoscopies of which 242,756 were screening colonoscopies. The rate of overuse ranged credibly from 17 to $25.7 \%$.

DISCUSSION: This study demonstrates that screening colonoscopy is regularly performed in the USA more often, and in populations older or younger, than recommended by national guidelines. Such overuse wastes resources and places patients at unnecessary risk of harm. Efforts to reduce non-indicated screening colonoscopy are needed.

KEY WORDS: overuse; screening colonoscopy; low-value care; harms.

J Gen Intern Med 37(7):1754-62

DOI: $10.1007 /$ s11606-021-07263-w

(C) The Author(s) under exclusive licence to Society of General Internal Medicine 2021

\section{INTRODUCTION}

For more than two decades, the United States Preventive Services Task Force (USPSTF) and other national organizations have recommended screening for colorectal cancer, ${ }^{1,2}$ with either a stool-based or direct visualization test. ${ }^{3}$ While screening colonoscopy poses the risk of serious harm, the USPSTF concluded this risk is outweighed by potential benefits, depending upon age, risk factors, and prior colonoscopic findings, and if performed at the recommended schedule for average-risk adults between 45 and 75 years old. ${ }^{1}$ Guidelines issued by the U.S. Multi-Society Task Force are similar to those of the USPSTF. ${ }^{2}$

Screening colonoscopy is often performed on patients younger or older than the age range specified in national guidelines, or at shorter intervals than recommended. Such non-indicated use of the procedure is considered low-value care, or overuse. Several studies have reported on the incidence of non-indicated colonoscopy in the USA, ${ }^{5-8}$ typically within specific demographic or regional groups. A recent systematic review and meta-analysis found that endoscopists recommend screening colonoscopy at shorter intervals than suggested by guidelines to nearly half of their patients. ${ }^{9}$ However, this systematic review did not examine the actual rate at which inappropriate colonoscopies are performed. This study is the first systematic review of the rate of non-indicated screening colonoscopy performed within the USA.

This study reviews rates of completed, non-indicated colonoscopy in order to estimate a credible range of the rate of actual overuse. In a future study, the authors plan to use the results of this systematic review, together with a parallel systematic review of severe harms from the procedure, to estimate national rates of harm from inappropriate screening colonoscopy. ${ }^{10}$

\section{METHODS}

We conducted a systematic review of the overuse of optical colonoscopy for the screening of colorectal cancers. We followed methods outlined in the Preferred Reporting Items for Systematic Reviews and Meta-Analyses (PRISMA) and 
the reporting recommendations of the Meta-analysis of Observational Studies in Epidemiology group (MOOSE). ${ }^{11,12}$

\section{Data Sources}

Eligible trials were identified by searches of PubMed and Embase. Studies published from January 1, 2002, to January 23, 2019, were included in the searches. Search strategies are included in Supplement 1.

\section{Eligibility Criteria}

Studies evaluating overuse were considered eligible if the study: (1) was performed in a standard endoscopy suite in the USA; (2) used US national guidelines including the USPSTF and the multi-society task force to define overuse in a US sample; (3) enrolled patients after 2002, when the USPSTF began recommending colonoscopy for colorectal cancer (CRC) screening (4) reported on completed screening colonoscopies; and (5) included asymptomatic patients at average risk of developing colon cancer. Studies were excluded if they enrolled patients with high-risk classification such as personal history of CRC, inflammatory bowel disease, signs of possible CRC, and family history of CRC because the recommendations for screening such patients are different from those for patients of average risk. Studies including only surveillance colonoscopies alone were also excluded as were studies that did not quantify estimates of overuse and were written in a language other than English.(6) Repeat colonoscopies which occurred less than 6 months after the initial colonoscopy were excluded as these occurred most likely due to inadequate bowel prep, and should not be labeled as inappropriate.

\section{Study Identification}

Two independent investigators (J.F. and A.H.) screened articles by title and abstract using predefined inclusion and exclusion criteria and a standardized data form. If the article did not meet inclusion criteria based on the abstract, the full text was not reviewed. The inclusion of full text was decided by consensus, and a third reviewer (K.L.) independently resolved all cases of discordance. Inter-reviewer reliability was assessed and reported using Cohen's kappa statistic.

\section{Data Extraction and Outcomes}

Paired reviewers (J.F., A.H., K.L., S.B.) independently abstracted results from each article in duplicate. The included data were as follows: study characteristics, patient characteristics, population analyzed, definition of overuse, total screening colonoscopies identified, and incidence of non-indicated screening colonoscopy.

The primary outcome for overuse analysis was the percentage of total screening colonoscopies not adherent with national guidelines. This included colonoscopies performed in patients younger or older than those specified by the prior
USPSTF guidelines available when studies were performed (colonoscopy performed in patients over 75 years old without indication; and screening colonoscopies completed on patients with a life expectancy of less than 10 years), and those performed more often than recommended (screening colonoscopy completion less than 9 years after normal screening colonoscopy).

The primary outcome for overuse analysis was the percentage of total screening colonoscopies not adherent with national guidelines. This included colonoscopies performed in patients younger or older than those specified by national guidelines available when studies were performed (colonoscopy performed in patients over 75 years old without indication; and screening colonoscopies completed on patients with a life expectancy of less than 10 years). In addition, screening colonoscopies performed more often than recommended were included as well (screening colonoscopy completion less than 9 years after normal screening colonoscopy).

\section{Data Synthesis and Analysis}

Based on the degree of methodological heterogeneity and $I^{2}$ among included studies, a narrative synthesis was deemed more appropriate than meta-analysis; therefore, no data were pooled. Instead, we offer a credible range for an estimate of overuse based on studies reporting the lowest and highest rates. To provide a consistently defined rate of overuse across studies, we calculated the total number of non-indicated colonoscopies per total number of screening colonoscopies performed for all studies meeting inclusion criteria.

\section{Risk of Bias Assessment}

Each article was reviewed in full by two authors (SB, JF, AH, $\mathrm{KL}$ ). There is no standardized risk of bias assessment tool appropriate for overuse studies. Therefore, we used the following parameters to evaluate study quality: study design (retrospective case-control, case-series, cohort), data collection (manual chart review, EHR query), definition of overuse (consistent with national guidelines or not consistent), and how the data were analyzed.

\section{RESULTS}

Of 772 citations, 730 articles were excluded based on title and abstract. Inter-reviewer reliability as assessed by Cohen's kappa was 0.7 ("substantial" agreement). Forty-two studies were reviewed in full text. Of these, one was removed based on non-English language, eleven were removed based on study design, seven were removed based on population studied, and seventeen did not report on overuse (Fig. 1). Six studies met eligibility criteria, including a total of 459,503 colonoscopies of which 242,756 were screening colonoscopies (Table 1). ${ }^{(5-}$ $8,13,14)$ Studies ranged in sample size from 1,027 to 88,754 


\section{Identification of studies via databases and registers}

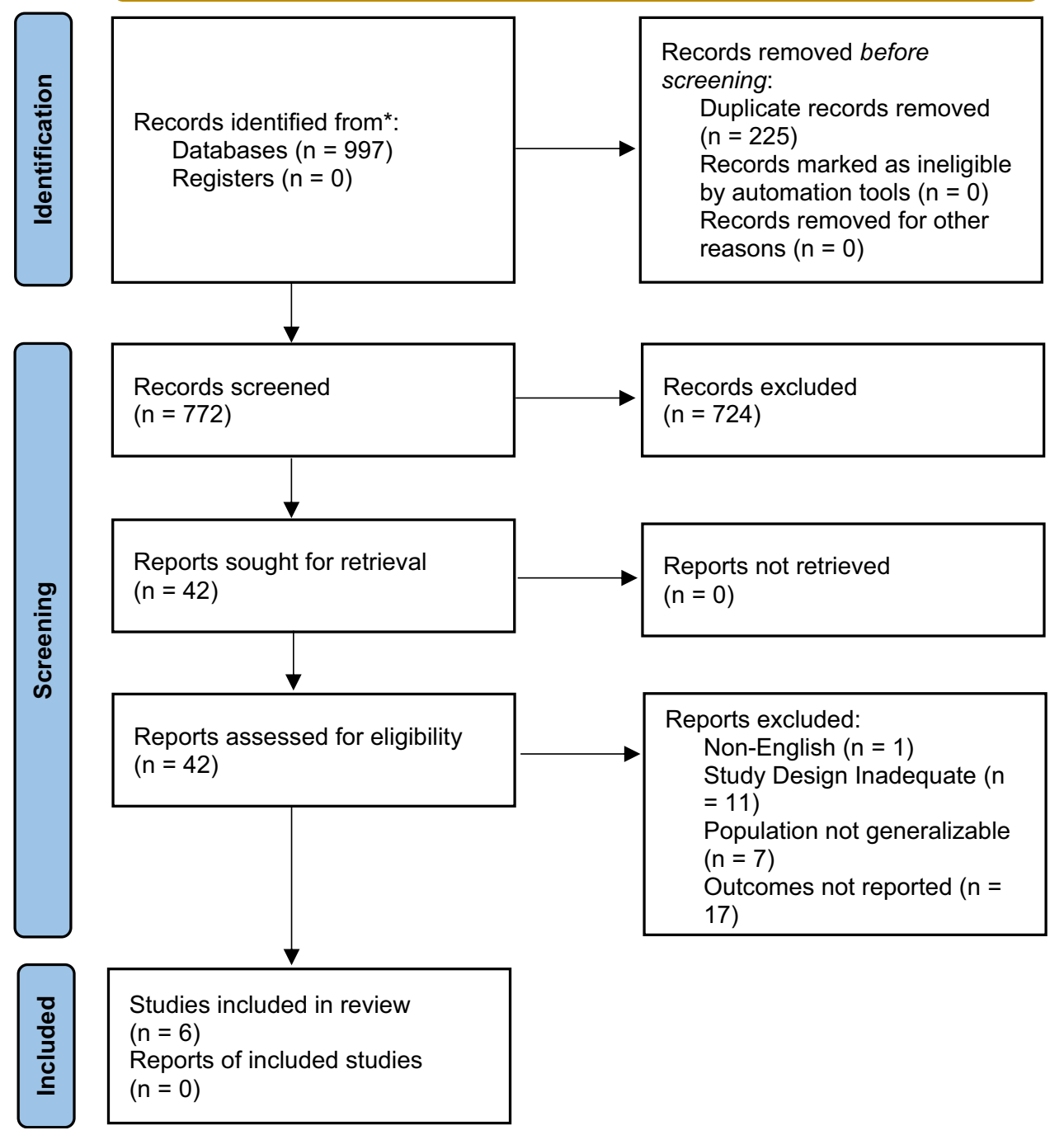

Figure 1 PRISMA 2020 diagram of overuse studies queried from two databases, resulting in 6 eligible articles.

screening colonoscopies and patients ranged in age from under 40 to 102 years. Reported data to calculate median or mean age were not available. Five studies included national samples: three from Medicare and two from the Veterans Health Administration. Two studies included local samples: one used nationwide Medicare data and also included a detailed examination of $100 \%$ of Texas Medicare beneficiaries, while another examined colonoscopies performed within a large private health system within Massachusetts (Table 1).

All studies excluded patients at high risk for CRC. All studies other than Murphy et al. ${ }^{6}$ excluded cases potentially representing diagnostic colonoscopies (Table 2). Studies specifically identified exclusion criteria to avoid misclassifying diagnostic colonoscopies: three studies excluded 12 symptoms, diagnoses, and/or prior procedures ${ }^{8,13,14}$ and Saini et al. ${ }^{7}$ excluded based on 25 criteria.

Methodologically, Sheffield et al., ${ }^{14}$ Mittal et al., ${ }^{8}$ and Goodwin et al. ${ }^{13}$ identified screening colonoscopies and exclusion criteria via claims data using ICD-9 and CPT codes.
Murphy et al. ${ }^{6}$ used a combination of CPT and manual medical record review for data collection. Kruse et al. ${ }^{5}$ and Saini et al. ${ }^{7}$ used an electronic health record algorithm to identify screening colonoscopies; in addition, Saini et al. ${ }^{7}$ used the algorithm to identify screening colonoscopy overuse. The electronic algorithm of Kruse et al. ${ }^{5}$ had previously been demonstrated to identify screening colonoscopy with a sensitivity of $88 \%$ and specificity of $96 \%$, when compared to manual review. To evaluate their algorithm, Saini et al. ${ }^{7}$ performed a manual review of 3,000 colonoscopies; they found their algorithm had a sensitivity of $20 \%$ for identifying overuse of screening colonoscopy and specificity of $97 \%$.

All five studies that examined early repeat colonoscopy defined this as colonoscopy performed less than 9 years after prior negative screening colonoscopy. Three studies used an observation period of time following a negative index colonoscopy; Murphy et al. ${ }^{6}$ followed patients 6 years; Goodwin et al. ${ }^{13}$ followed for 5-7 years, while Kruse et al. ${ }^{5}$ collected data on index colonoscopy over a 9-year period, with 
Table 1 Overuse Study Characteristics

\begin{tabular}{|c|c|c|c|c|c|c|c|c|}
\hline$\overline{\text { Study }}$ & Year & $\begin{array}{l}\text { Patient } \\
\text { age }\end{array}$ & Setting & $\begin{array}{l}\text { Data collection } \\
\text { method }\end{array}$ & Study type & $\begin{array}{l}\text { Years } \\
\text { observed } \\
\text { between } \\
\text { colonoscopy }\end{array}$ & $\begin{array}{l}\text { Total } \\
\text { screening } \\
\text { colonoscopies }\end{array}$ & Overuse criteria \\
\hline Kruse $^{22}$ & 2014 & $50-65$ & $\begin{array}{l}\text { Academically } \\
\text { Affiliated } \\
\text { Clinics in } \\
\text { Massachusetts }\end{array}$ & $\begin{array}{l}\text { An algorithm- } \\
\text { based EHR, using } \\
\text { diagnostic, and } \\
\text { procedure codes }\end{array}$ & $\begin{array}{l}\text { Early repeat } \\
\text { colonoscopy } \\
\text { after index } \\
\text { exam }\end{array}$ & $1-9$ years & 1,484 & $\begin{array}{l}\text { Repeat colonoscopy } \\
\text { performed without } \\
\text { indication }\end{array}$ \\
\hline Goodwin $^{40}$ & 2011 & $>66$ & $\begin{array}{l}\text { Medicare 5\% } \\
\text { National } \\
\text { Representative }\end{array}$ & $\begin{array}{l}\text { Claims data using } \\
\text { ICD-9 and CPT } \\
\text { codes }\end{array}$ & $\begin{array}{l}\text { Early repeat } \\
\text { colonoscopy } \\
\text { after index } \\
\text { exam }\end{array}$ & $5-7$ years & $19,213^{*}$ & $\begin{array}{l}\text { Repeat colonoscopy } \\
\text { performed without } \\
\text { indication }\end{array}$ \\
\hline Mittal $^{41}$ & 2014 & $>65$ & $\begin{array}{l}\text { Medicare 5\% } \\
\text { National } \\
\text { Representative }\end{array}$ & $\begin{array}{l}\text { Claims data using } \\
\text { ICD-9 and CPT } \\
\text { codes }\end{array}$ & $\begin{array}{l}\text { Cross-sectional } \\
\text { identification } \\
\text { of screening } \\
\text { colonoscopy }\end{array}$ & $\mathrm{N} / \mathrm{a}$ & 57,597 & $\begin{array}{l}\text { Colonoscopy } \\
\text { performed on } \\
\text { patients with less } \\
\text { than } 10 \text { years life } \\
\text { expectancy } \dagger\end{array}$ \\
\hline Murphy $^{21}$ & 2016 & $50-64$ & $\begin{array}{l}\text { Veterans } \\
\text { Affairs Health } \\
\text { Care System }\end{array}$ & $\begin{array}{l}\text { CPT codes and } \\
\text { manual medical } \\
\text { record review }\end{array}$ & $\begin{array}{l}\text { Early repeat } \\
\text { colonoscopy } \\
\text { after index } \\
\text { exam }\end{array}$ & $5-6$ years & 1,027 & $\begin{array}{l}\text { Repeat colonoscopy } \\
\text { performed }\end{array}$ \\
\hline Saini $^{23}$ & 2016 & $>18$ & $\begin{array}{l}\text { Veterans } \\
\text { Affairs Health } \\
\text { Care System }\end{array}$ & $\begin{array}{l}\text { Abstraction } \\
\text { algorithm-based } \\
\text { on EHR ICD-9 } \\
\text { and CPT codes }\end{array}$ & $\begin{array}{l}\text { Cross-sectional } \\
\text { identification } \\
\text { of screening } \\
\text { colonoscopy }\end{array}$ & 9 years & 88,754 & $\begin{array}{l}\text { Screening } \\
\text { colonoscopy } \\
\text { performed without } \\
\text { indication; earlier } \\
\text { than recommended, } \\
\text { or within } 6 \text { months } \\
\text { of negative FOBT, } \\
\text { or in patients with } \\
\text { less than 6-month } \\
\text { life expectancy }\end{array}$ \\
\hline Sheffield $^{42}$ & 2013 & $>70$ & $\begin{array}{l}\text { Medicare } 100 \% \\
\text { Texas Claims }\end{array}$ & $\begin{array}{l}\text { Claims data using } \\
\text { ICD-9, HCPCS, } \\
\text { and CPT codes }\end{array}$ & $\begin{array}{l}\text { Cross-sectional } \\
\text { identification } \\
\text { of screening } \\
\text { colonoscopy }\end{array}$ & 9 Years & 74,681 & $\begin{array}{l}\text { Screening } \\
\text { colonoscopy earlier } \\
\text { than recommended } \\
\text { without clear } \\
\text { indication in patient } \\
\text { over } 70-75 \text { years old } \\
\text { or if greater than } \\
76 \text { years old without } \\
\text { diagnostic indication }\end{array}$ \\
\hline
\end{tabular}

* Calculated from data presented within the study

${ }^{+}$Using sex-specific model combining age and Elixhauser comorbidity index ${ }^{41}$

repeat screening colonoscopies identified during the same period. Saini et al. ${ }^{7}$ and Sheffield et al. ${ }^{14}$ were crosssectional studies and retrospectively identified colonoscopically normal screening colonoscopies in the 9 years prior to index colonoscopy (see Table 1).

The studies identified inappropriate screening colonoscopies using different exclusion criteria (see Table 2) and different methodologies, with various definitions of overuse. This resulted in different practical definitions of overuse. Murphy et al. ${ }^{6}$ and Goodwin et al. ${ }^{13}$ reported overuse as the total incidence of non-indicated colonoscopy per number of index screening colonoscopies with negative results as the denominator. These studies reported a rate of overuse of $16.4 \%$ and $23.5 \%$ respectively. Kruse et al. ${ }^{5}$ reported overuse as the number of non-indicated repeat colonoscopies as the numerator, and the total number of repeat colonoscopies as the denominator, finding an overuse rate of $88 \%$. Mittal et al. ${ }^{8}$ evaluated screening colonoscopy overuse by determining the percentage of colonoscopies performed on patients over the age of 65 with less than 10-year life expectancy for an overuse rate of $24.8 \%$. Sheffield et al. ${ }^{14}$ reported overuse as the percentage of screening colonoscopies performed earlier than recommended as the numerator, with total screening colonoscopies as the denominator, and found a rate of probable overuse of $18.9 \%$. Saini et al. ${ }^{7}$ calculated overuse in a manner similar to Sheffield et al., ${ }^{14}$ but in addition to earlier than recommended screening colonoscopy, they also considered inappropriate screening colonoscopies ( patients < 40 years, $>85$ years, life expectancy of less than 6 months, colonoscopy performed $<6$ months after negative fecal occult blood test). They found a rate of probable overuse of $17 \%$. Factors associated with increased rates of overuse were inconsistent across studies, except for follow-up recommendation adherence to guidelines, which both Kruse et al. and Murphy et al. identified guideline non-adherent follow-up recommendations to be associated with statistically significant increases in rates of overuse. Rates of overuse by patient characteristics can be found in Table 3 . 
Table 2 Study Exclusion Criteria

\begin{tabular}{|c|c|c|c|c|c|c|}
\hline$\overline{\text { Study }}$ & Kruse & Goodwin & Mittal & Murphy & Saini & Sheffield \\
\hline \multicolumn{7}{|l|}{ Exclusion criteria } \\
\hline All exclusion criteria identified in record in $\mathrm{X} 2$ months prior & & & & & $\mathrm{X}$ & \\
\hline Exclusion criteria of high risk for $\mathrm{CRC}$ in $\mathrm{X} 2$ months prior & & $\mathrm{X}$ & & & $\mathrm{X}$ & \\
\hline Exclusion criteria of high risk for $\mathrm{CRC}$ in $\mathrm{X} 0$ years prior & & & & $\mathrm{X}$ & & \\
\hline Exclusion criteria of high risk for CRC in Chart review & $\mathrm{X}$ & & & & & \\
\hline All exclusion criteria examine in 3 months prior & & & $\mathrm{X}$ & & & $\mathrm{X}$ \\
\hline Symptoms, diagnosis procedures on all claims data indicating diagnostic & & $\mathrm{X}$ & & & & \\
\hline colonoscopy in 3 months prior & & & & & & \\
\hline Excluded colonoscopies with symptoms listed by endoscopist for indication & $\mathrm{X}$ & & & & & \\
\hline Exclusion criteria of high risk for CRC in $\mathrm{X} 2$ months prior & & & & & & \\
\hline No clear exclusion criteria on repeat colonoscopies & & & & $\mathrm{X}$ & & \\
\hline \multicolumn{7}{|l|}{ High risk for CRC diagnosis } \\
\hline Hx of CRC & $\mathrm{X}^{*}$ & $\mathrm{X}$ & $\mathrm{X}$ & $\mathrm{X}+$ & $\mathrm{X}$ & $\mathrm{X}^{\dagger}$ \\
\hline Inflammatory bowel disease & & $\underset{\mathrm{X}}{\mathrm{X}}$ & $\mathrm{X}$ & & $\mathrm{X}$ & \\
\hline Familial polyposis syndromes & & $\mathrm{X}$ & & & & \\
\hline Colectomy & & & & & $\mathrm{X}$ & \\
\hline Colon polyps & & & & & $\mathrm{X}$ & \\
\hline Fam Hx of CRC & & $\mathrm{X}$ & $\mathrm{X}$ & & $\mathrm{X}$ & $\mathrm{X}$ \\
\hline \multicolumn{7}{|l|}{ Symptoms, diagnosis, or procedures } \\
\hline Barium enema & & $\mathrm{X}$ & $\mathrm{X}$ & & & $\mathrm{X}$ \\
\hline Abdominal CT scan & & $\mathrm{X}$ & $\mathrm{X}$ & & & $\mathrm{X}$ \\
\hline Anemia & & $\mathrm{X}$ & $\mathrm{X}$ & & $\mathrm{X}$ & $\mathrm{X}$ \\
\hline GI bleeding & & $\mathrm{X}$ & $\mathrm{X}$ & & $\mathrm{X}$ & $\mathrm{X}$ \\
\hline Constipation & & $\mathrm{X}$ & $\mathrm{X}$ & & $\mathrm{X}$ & $\mathrm{X}$ \\
\hline Diarrhea & & $\mathrm{X}$ & $\mathrm{X}$ & & $\mathrm{X}$ & $\mathrm{X}$ \\
\hline Abdominal pain & & $\mathrm{X}$ & $\mathrm{X}$ & & $\mathrm{X}$ & $\mathrm{X}$ \\
\hline Abdominal distention & & & & & $\mathrm{X}$ & \\
\hline Abdominal swelling & & & & & $\mathrm{X}$ & \\
\hline Iron-deficiency anemia & & & & & $\mathrm{X}$ & \\
\hline Ischemic bowel disease & & $\mathrm{X}$ & $\mathrm{X}$ & & & $\mathrm{X}$ \\
\hline Anorexia & & & & & $\mathrm{X}$ & \\
\hline Bowel obstruction & & & & & $\mathrm{X}$ & \\
\hline Change in bowel habits & & $\mathrm{X}$ & $X$ & & $\mathrm{X}$ & $\mathrm{X}$ \\
\hline Fecal incontinence & & & & & $\mathrm{X}$ & \\
\hline Heme-positive stool & & & & & $\mathrm{X}$ & \\
\hline Hemorrhage of rectum/anus & & & & & $\mathrm{X}$ & \\
\hline Nausea/vomiting & & & & & $\mathrm{X}$ & \\
\hline Weight loss & & $\mathrm{X}$ & $\mathrm{X}$ & & $\mathrm{X}$ & $\mathrm{X}$ \\
\hline Hx of colon polyps & & & & & $\mathrm{X}$ & \\
\hline Diverticulitis with hemorrhage & & & & & $\mathrm{X}$ & \\
\hline Diverticulosis with hemorrhage & & & & & $\mathrm{X}$ & \\
\hline Colitis radiation & & & & & $\mathrm{X}$ & \\
\hline Intussusception & & & & & $\mathrm{X}$ & \\
\hline Paralytic ileus & & & & & $\mathrm{X}$ & \\
\hline Megacolon & & & & & $\mathrm{X}$ & \\
\hline Irritable colon & & & & & $\mathrm{X}$ & \\
\hline Colonoscopy performed during hospitalization & & & & & $\mathrm{X}$ & \\
\hline Irritable bowel syndrome & & $\mathrm{X}$ & $\mathrm{X}$ & & & $\mathrm{X}$ \\
\hline Hemorrhoid & & $\mathrm{X}$ & $\mathrm{X}$ & & & $\mathrm{X}$ \\
\hline Total number of exclusions & $\mathrm{n} / \mathrm{a}$ & 12 & 12 & $\mathrm{n} / \mathrm{a}$ & 25 & 12 \\
\hline
\end{tabular}

"Kruse et al. did not exclude the family history of CRC; however, they repeated the analysis with and without patients with family history and it did not alter the analysis

${ }^{\dagger}$ Sheffield et al. included those with family history of CRC; however, they labeled early repeat colonoscopy in those with a family history as appropriate, and therefore, family history of CRC was excluded from the overuse group

* Murphy et al. did not specifically exclude family hx of CRC, but their sample was a cohort of patients taken from a previous study31 which did exclude those with a family history of CRC

To make the rate of overuse comparable between studies, all rates were converted to a consistently defined rate of overuse, defined as the total number of non-indicated colonoscopies per total number of screening colonoscopies performed. Three of the six studies had used this definition: Saini et al., Sheffield et al., and Mittal et al., with corresponding overuse rates of $17 \%$, $18.9 \%$, and $24.8 \%$ respectively. While the three additional studies calculations were made using data reported in the study for Goodwin et al., Murphy et al., and
Kruse et al., with corresponding overuse rates of $19 \%$, $20.3 \%$, and $25.7 \%$ respectively.

\section{Credible range of screening colonoscopy overuse}

The credible range of the rate of overuse of screening colonoscopy was $17 \%^{7}$ to $25.7 \%^{5}$ (Table 4 ). At the low end of the credible range, the rate of $17.0 \%$ found by Saini et al. ${ }^{7}$ is likely an underestimate of the true rate of overuse. We believe this to be the case due to the practice location in Saini et al., ${ }^{7}$ 
Table 3 Rates of Overuse by Patient Characteristics

\begin{tabular}{|c|c|c|c|c|c|c|}
\hline & $\begin{array}{l}\text { Kruse } \\
\text { et al. }\end{array}$ & $\begin{array}{l}\text { Goodwin } \\
\text { et al. }\end{array}$ & $\begin{array}{l}\text { Mittal } \\
\text { et al. }\end{array}$ & $\begin{array}{l}\text { Murphy } \\
\text { et al. }\end{array}$ & $\begin{array}{l}\text { Saini } \\
\text { et al. }^{7}\end{array}$ & $\begin{array}{l}\text { Sheffield } \\
\text { et al. }{ }^{14}\end{array}$ \\
\hline $\begin{array}{l}\text { Study-reported overuse of screening colonoscopy (different } \\
\text { overuse definitions used preclude comparability across studies) }\end{array}$ & $88 \%$ & $23.50 \%$ & $24.80 \%$ & $16.4 \%$ & $17 \%$ & $18.90 \%$ \\
\hline \multicolumn{7}{|l|}{ Patient characteristics } \\
\hline Male & $88 \%$ & $26 \%$ & $32 \%$ & $16.6 \%$ & & $21.2 \%$ \\
\hline Female & $89 \%$ & $21.6 \%$ & $17.6 \%$ & $15.1 \%$ & & $17.1 \%$ \\
\hline \multicolumn{7}{|l|}{ Age } \\
\hline $\begin{array}{r}<40 \\
40-49\end{array}$ & & & & & $8 \%$ & \\
\hline $\begin{array}{l}40-49 \\
50-59\end{array}$ & & & & & & \\
\hline $\begin{array}{l}50-59 \\
60-65\end{array}$ & $86 \%$ & & & & & \\
\hline $\begin{array}{l}60-65 \\
66-69\end{array}$ & $89 \%$ & & & & & \\
\hline $\begin{array}{l}66-69 \\
66-74\end{array}$ & & $28 \%$ & & & & \\
\hline $\begin{array}{l}66-74 \\
70-74\end{array}$ & & & $5.9 \%$ & & & \\
\hline $70-74$ & & $26.6 \%$ & & & & $7.9 \%$ \\
\hline $75-79$ & & $20.7 \%$ & & & & \\
\hline $76-85$ & & & $59.5 \%$ & & & $31.7 \%$ \\
\hline$>=80$ & & $10.8 \%$ & & & & \\
\hline$>=86$ & & & $100 \%$ & & $1 \%$ & $17.3 \%$ \\
\hline \multicolumn{7}{|l|}{ Race } \\
\hline White & & $23.6 \%$ & $24.9 \%$ & $17.7 \%$ & & $19.2 \%$ \\
\hline Black & & $21.6 \%$ & $23.2 \%$ & & & $16 \%$ \\
\hline Hispanic & & & $24.8 \%$ & & & $14.2 \%$ \\
\hline Other & & & $22.3 \%$ & $13.1 \%$ & & $17.7 \%$ \\
\hline \multicolumn{7}{|l|}{ No. of comorbidities } \\
\hline 0 & & $21.7 \%$ & & & & $23.6 \%$ \\
\hline 1 & & $26.2 \%$ & & & & $22.3 \%$ \\
\hline 2 & & $23.6 \%$ & & & & $20.5 \%$ \\
\hline$\geq 3$ & & $22 \%$ & & & & $12.3 \%$ \\
\hline \multicolumn{7}{|l|}{ Follow-up recommendation } \\
\hline Adherent & $76 \%$ & & & $10.1 \%$ & & \\
\hline Non-adherent & $95 \%$ & & & $30 \%$ & & \\
\hline \multicolumn{7}{|l|}{ Region } \\
\hline New England & & $22.7 \%$ & & & & \\
\hline Northeast & & & & $25.6 \%$ & & \\
\hline Middle Atlantic & & $29.3 \%$ & & & & \\
\hline East North Central & & $24.5 \%$ & & & & \\
\hline Midwest & & & & $14.9 \%$ & & \\
\hline West North Central & & $25 \%$ & & & & \\
\hline South Atlantic & & $21.9 \%$ & & & & \\
\hline East South Central & & $22.8 \%$ & & & & \\
\hline South & & & & $13.5 \%$ & & \\
\hline West South Central & & $22 \%$ & & & & \\
\hline Mountain Pacific & & $19.9 \%$ & & & & \\
\hline West & & & & $19.8 \%$ & & \\
\hline \multicolumn{7}{|l|}{ Rural/urban } \\
\hline Metropolitan & & $24 \%$ & $25.1 \%$ & & & $19.4 \%$ \\
\hline Non-metropolitan & & $22.2 \%$ & $23.8 \%$ & & & $16.9 \%$ \\
\hline Rural & & $21.4 \%$ & $23.9 \%$ & & & $18.1 \%$ \\
\hline \multicolumn{7}{|l|}{ Place of service } \\
\hline Office & & $26.9 \%$ & & & & $22.5 \%$ \\
\hline Hospital & & $23.3 \%$ & & & & $16.2 \%$ \\
\hline Ambulatory center & & $23.4 \%$ & & & & $22.6 \%$ \\
\hline \multicolumn{7}{|l|}{ Education } \\
\hline Q1 & & $24.5 \%$ & $24.6 \%$ & & & $21.8 \%$ \\
\hline Q2 & & $24.5 \%$ & $25.9 \%$ & & & $20 \%$ \\
\hline Q3 & & $22.6 \%$ & $24.7 \%$ & & & $18.6 \%$ \\
\hline Q4 & & $22.2 \%$ & $24 \%$ & & & $15.3 \%$ \\
\hline \multicolumn{7}{|l|}{ Colonoscopist specialty } \\
\hline Gastroenterologist & & $23.6 \%$ & & $15.3 \%$ & & $18.8 \%$ \\
\hline Generalist & & $20.6 \%$ & & $18.3 \%$ & & $16.5 \%$ \\
\hline Surgeon & & $23.5 \%$ & & $17.8 \%$ & & $20.2 \%$ \\
\hline Other & & $27.3 \%$ & & $19.9 \%$ & & $14.1 \%$ \\
\hline
\end{tabular}

${ }^{*}$ For rates of overuse with a consistent definition of overuse see Table 4

their exclusion criteria, overuse definition, and data collection methods. Saini et al. ${ }^{7}$ was performed in the VA system, which is known to represent a lower level of overuse generally, as the VA system has reduced rates of many unnecessary interventions. ${ }^{15}$ The overuse definition and data collection methods in Saini et al. ${ }^{7}$ used a methodology designed to be highly specific at the cost of sensitivity, ensuring their estimate of overuse would not overestimate but rather would underestimate the true rate. Saini et al. ${ }^{7}$ contained the most stringent exclusion criteria of all 6 studies, to ensure no diagnostic colonoscopies would be incorrectly counted as overuse, and their stringent exclusion criteria likely categorized many 
Table 4 Calculated Rate of Overuse of Screening Colonoscopy*

\begin{tabular}{lcll}
\hline \hline Study & $\begin{array}{l}\text { Total screening } \\
\text { colonoscopies }\end{array}$ & $\begin{array}{l}\text { Incidence of } \\
\text { screening } \\
\text { colonoscopy } \\
\text { overuse }\end{array}$ & $\begin{array}{l}\text { Screening } \\
\text { colonoscopy } \\
\text { overuse rate }\end{array}$ \\
\hline $\begin{array}{l}\text { Kruse } \\
\text { et al. }\end{array}$ & 1,484 & 382 & $25.70 \%$ \\
$\begin{array}{l}\text { Goodwin } \\
\text { et al. }\end{array}$ & $19,213 \dagger$ & 3,656 & $19.0 \%$ \\
$\begin{array}{l}\text { Mittal } \\
\text { et al. }\end{array}$ & 57,597 & 14,284 & $24.80 \%$ \\
$\begin{array}{l}\text { Murphy } \\
\text { et al. }\end{array}$ & 1,027 & 208 & $20.30 \%$ \\
$\begin{array}{l}\text { Saini } \\
\text { et al. }\end{array}$ & 88,754 & 15,088 & $17 \%$ \\
$\begin{array}{l}\text { Sheffield } \\
\text { et al. }\end{array}$ & 74,681 & 14,115 & $18.90 \%$ \\
\hline
\end{tabular}

*Rates calculated using data from papers and a single definition of overuse

${ }^{*}$ Data obtained from direct correspondence with the author

inappropriate screening colonoscopies as appropriate diagnostic colonoscopies. Likewise, their definition of overuse, likely led them to count many low-value screenings as appropriate, including exams in patients at average risk between ages 40 and 45 and those over 75 with less than 10-year life expectancy. Both populations of patients are not considered appropriate candidates for screening by the USPSTF guidelines. ${ }^{2,4}$ The data collection method used by Saini et al. ${ }^{7}$ involved an electronic measure which they internally validated by comparing the measure to a manual review of a select number of charts. It demonstrated high specificity (97\%) and low sensitivity (20\%). This low sensitivity suggests misclassification of overuse as appropriate. For these reasons, we are confident that the true national rate of overuse is unlikely to be below the results found in this study.

The high interval of the credible range identified by Kruse et al., ${ }^{5} 25.7 \%$, is the highest rate of overuse of screening colonoscopy identified by any previously published study. Kruse et al. ${ }^{5}$ used an electronic algorithm to identify overuse that had previously been found to identify overuse of screening colonoscopy with a sensitivity of $88 \%$ and specificity of $96 \%$. Given the relatively high sensitivity of their electronic algorithm, most cases of overuse that occurred during the study period were likely identified. However, Kruse et al. ${ }^{5}$ did not follow a large percentage of patients for a total of 9 years as their median follow-up time was 6.1 years. This suggests the true rate of overuse of screening colonoscopy may be higher than the result found by Kruse et al. ${ }^{5}$ Despite these shortcomings, Kruse et al. ${ }^{5}$ represent the highest rate of overuse identified by this systematic review.

\section{DISCUSSION}

Screening colonoscopy is recommended as a first-line option for colorectal cancer screening by most national guidelines within the USA. ${ }^{2,16-18}$ When adherent to guidelines, screening colonoscopy is thought to reduce colorectal cancer mortality and incidence, with benefits outweighing harms. ${ }^{19}$ However, screening colonoscopy performed more often than recommended by guidelines or in populations older or younger than recommended wastes resources and places patients at risk unnecessarily. This systematic review found that between 17 and $25.7 \%$ of screening colonoscopies occurring in the USA are likely overuse.

The annual number of screening colonoscopies performed in the USA was estimated to be 6.3 million in $2012 .{ }^{20}$ Given the credible range of inappropriate screening colonoscopies identified by this study, this would translate to at least 1 million unnecessary colonoscopies occurring in the USA annually. This estimate should raise concern, due to both the increased cost to the healthcare system and risks to patient safety in the context of preventable harms [BMJ REF to come to SB]. Major harms associated with colonoscopy include significant bleeding requiring transfusion, GI perforation, and death. ${ }^{21}$ Even without serious harm, colonoscopy is likely a burdensome experience for most patients given the discomfort of bowel preparation, ${ }^{22}$ the out-of-pocket cost of the procedure and associated sedation, work days lost, and postprocedural pain and recovery.

In addition to the potential harm caused by low-value colonoscopy, the financial costs to the healthcare system are substantial. A recent CDC analysis estimated the average cost of screening colonoscopy in the USA to be $\$ 3,153 .{ }^{23}$ Applying the CDC estimate to the credible range identified in this study suggests more than $\$ 3$ billion are wasted annually on unnecessary screening colonoscopies.

Like the overuse of many other medical interventions, several diverse factors drive non-indicated screening colonoscopy. These drivers may be patient-based, clinicianbased, or system-based. For example, the Veterans Administration (VA) system has been found to have lower rates of unnecessary medical interventions in general. ${ }^{15}$ It has been proposed the VA may have lower rates of overuse than the healthcare system as a whole due to flat payments to providers rather than fee for service. ${ }^{24}$ Additionally, the insulated nature of the VA system might reduce overuse. Calls for payment models that replace fee for service have been raised specifically for gastroenterology, with one expected benefit being a reduction in unnecessary screening colonoscopies. ${ }^{25}$.

Two studies identified by this systematic review found nonindicated early screening colonoscopy was associated with the endoscopist's recommendation, with an odds ratio of 3.86.3 . $^{5,6}$ Inappropriate recommendation for early repeat colonoscopy may be a common cause of overuse; the New York City Colonoscopy Quality Benchmarking Group found that $79.6 \%$ of endoscopists incorrectly recommended followup after normal colonoscopy, with more than half of endoscopists recommending follow-up sooner than five years. ${ }^{26}$ Non-indicated recommendations by clinicians may stem from lack of awareness of the USPSTF and MultiSociety Task Force guidelines. ${ }^{27}$. 
On the patient side, demand for non-indicated screenings ${ }^{28}$ may be an unintended consequence of public health messaging, which often encourages screening without providing balanced information about frequency, age limits, or the potential for harm. Patient-facing education, including improved public health messaging, may reduce inappropriate patient demand.

Given the ongoing COVID-19 pandemic, non-indicated screening colonoscopy raises additional risks for both the patient and the endoscopy staff. A study from Italy found $4.2 \%$ of endoscopy staff contracted COVID by March 21, at a time when $0.078 \%$ of the country had tested positive (Ourworldindata.org), suggesting endoscopy staff are at heightened risk of COVID infection. ${ }^{29}$ The risk of iatrogenic COVID transmission to patients during colonoscopy has not been clearly identified, but the same study from Italy found $1 \%$ of patients developed COVID-like symptoms within 15 days of endoscopy. ${ }^{29}$ However, large or small the risk of COVID transmission from colonoscopy may be, it is entirely avoidable for non-indicated colonoscopy. For this reason, the ASGE recommended delaying elective screening colonoscopies, ${ }^{30}$ a recommendation that has likely had the unintended benefit of reducing overuse. As screening colonoscopy is resumed, special attention should be paid to colonoscopies non-adherent to the guidelines, to avoid the unnecessary risk of COVID transmission in addition to the previously identified risks of colonoscopy.

Indeed, all risks of harm from the overuse of screening colonoscopies are potentially preventable. While there are increasing numbers of reports documenting the rate of overuse, few studies to date have examined the rate of harm it causes. Having that information available for clinicians and patients could help them avoid it. ${ }^{31}$ We plan to use the results from this study for a future paper to estimate rates of harm from overuse of screening colonoscopy.

\section{Limitations}

Repeat colonoscopies due to inadequate bowel preparation may have been labeled as overuse leading to an overestimate of overuse. However, studies evaluating repeat colonoscopies occurring less than 6 months after initial colonoscopy were excluded, making it unlikely that repeat colonoscopies were included in the rates of overuse in this analysis. Nearly all of the studies identified in this systematic review emphasized specificity at the cost of sensitivity. This ensures that the rate of overuse identified by the studies is very unlikely to overestimate the true rate of overuse of screening colonoscopy. In addition, the only study which used a more sensitive data collection method, Kruse et al., ${ }^{5}$ did not follow patients long enough after index colonoscopy to identify all cases of overuse. Thus, the credible range offered by this systematic review represents a reliable low estimate, with the true rate of overuse almost certainly above the low estimate provided. The true rate of overuse of screening colonoscopy could also be higher than the high end of the credible range.

\section{CONCLUSION}

Unnecessary screening colonoscopy is common within the USA and occurs in 17 to $25.7 \%$ of all screening colonoscopies. This overuse increases the cost of healthcare and inflicts harms on patients unnecessarily. These findings should provide additional motivation for both patients and clinicians to eliminate inappropriate colorectal cancer screening by following national cancer screening guidelines.

Supplementary Information: The online version contains supplementary material available at https://doi.org/10.1007/s11606-021o7263-w.

Acknowledgements: We are grateful for the contributions of Robert Ballieu (methodology), Richelle Cooper (conceptualization), Julia Healey (correspondence), Jerry Hoffman (conceptualization), Anuradha Jetty (formal analysis), and Elizabeth Wilkinson (formal analysis).

Corresponding Author: Joseph Fraiman, MD; New Orleans, USA (e-mail: Josephfraiman@gmail.com).

Author Contribution JF: methodology, systematic review process, writing of original draft, review and editing; SB: conceptualization, systematic review process, writing of original draft, review and editing, supervision; MS: methodology, validation, data curation, review of drafts and editing; KL: systematic review process, validation, review of drafts and editing; AH: methodology, systematic review process, validation, data curation, formal analysis, review and editing.

Funding This work was supported by the Robert Wood Johnson Foundation through grant number 75223. The funders had no role in design, execution, analysis, or writing of this study.

\section{Declarations:}

Conflict of Interest: The authors declare that they do not have a conflict of interest.

\section{REFERENCES}

1. Davidson, K. W., Barry, M. J., Mangione, et al. Screening for Colorectal Cancer: US Preventive Services Task Force Recommendation Statement. JAMA. 2021;325(19), 1965-1977.

2. Rex DK, Boland CR, Dominitz JA, et al. Colorectal cancer screening: recommendations for physicians and patients from the U.S. multi-society task force on colorectal cancer. Gastroenterology. 2017;153:307-23.

3. [3] Lin, J. S., Piper, M. A., Perdue, L. A., et al. Screening for colorectal cancer: updated evidence report and systematic review for the US Preventive Services Task Force. Jama 315.23 2016: 2576-2594.

4. US Preventive Services Task Force. Colorectal screening draft recommendation statement. October 27, 2020. Available at: https://www. uspreventiveservicestaskforce.org/uspstf/draft-recommendation/colorectal-cancer-screening3. Accessed January 21, 2021.

5. Kruse GR, Khan SM, Zaslavsky AM, Ayanian JZ, Sequist TD. Overuse of colonoscopy for colorectal cancer screening and surveillance. J Gen Intern Med. 2015;30(3) 277-83.

6. Murphy CC, Sandler RS, Grubber JM, Johnson MR, Fisher DA Underuse and overuse of colonoscopy for repeat screening and surveillance in the Veterans health administration. Clin Gastroenterol Hepatol. 2016; 14:436-44.e1.

7. Saini SD, Powell AA, Dominitz JA, et al. Developing and testing an electronic measure of screening colonoscopy overuse in a large integrated healthcare system. J Gen Intern Med. 2016;31 Suppl 1:53-60. 
8. Mittal S, Lin Y-L, Tan A, Kuo Y-F, El-Serag HB, Goodwin JS. Limited life expectancy among a subgroup of Medicare beneficiaries receiving screening colonoscopies. Clin Gastroenterol Hepatol Off Clin Pract $\mathbf{J}$ Am Gastroenterol Assoc. 2014; 12(3):443-450.

9. Djinbachian $\mathrm{R}$, Dubé AJ, Durand $\mathrm{M}$, et al. Adherence to postpolypectomy surveillance guidelines: a systematic review and metaanalysis. Endoscopy. 2019;51:673-83.

10. Alison N. Huffstetler, A, Fraiman, J, Brownlee, S, Stoto, MA, Lin, KW, An Estimate of Severe Harms in Screening Colonoscopy: A Systematic Review, Manuscript submitted for publication.

11. Hutton B, Salanti G, Caldwell DM, et al. The PRISMA extension statement for reporting of systematic reviews incorporating network meta-analyses of health care interventions: checklist and explanations. Ann Intern Med. 2015;162:777-84.

12. Stroup DF, Berlin JA, Morton SC, et al. Meta-analysis of observational studies in epidemiology: a proposal for reporting. Meta-analysis Of Observational Studies in Epidemiology (MOOSE) group. JAMA. 2000;283:2008-12.

13. Goodwin JS, Singh A, Reddy N, Riall TS, Kuo YF. Overuse of screening colonoscopy in the Medicare population. Arch Intern Med. 2011;171:1335-43.

14. Sheffield KM, Han Y, Kuo Y-F, Riall TS, Goodwin JS. Potentially inappropriate screening colonoscopy in Medicare patients: variation by physician and geographic region. JAMA Intern Med. 2013;173(7):542550.

15. O'Hanlon C, Huang C, Sloss E, et al. Comparing VA and Non-VA quality of care: a systematic review. J Gen Intern Med. 2017;32:105-21.

16. Bibbins-Domingo K, Grossman DC, Curry SJ, et al. Screening for colorectal cancer: US preventive services task force recommendation statement. JAMA. 2016;315:2564-75.

17. Rex DK, Johnson DA, Anderson JC, Schoenfeld PS, Burke CA, Inadomi JM. American College of Gastroenterology guidelines for colorectal cancer screening 2009 [corrected]. Am J Gastroenterol. 2009;104:739-50.

18. Wilt TJ, Harris RP, Qaseem A. Screening for cancer: advice for high-value care from the American College of Physicians. Ann Intern Med. 2015; 162:718-25.

19. Zauber AG, Winawer SJ, O'Brien MJ, et al. Colonoscopic polypectomy and long-term prevention of colorectal-cancer deaths. N Engl J Med. 2012;366:687-96

20. Joseph DA, Meester RG, Zauber AG, et al. Colorectal cancer screening: estimated future colonoscopy need and current volume and capacity. Cancer. 2016;122:2479-86.
21. Kothari ST, Huang RJ, Shaukat A, et al. ASGE review of adverse events in colonoscopy. Gastrointest Endosc. 2019;90:863-76.e33.

22. Gluecker TM, Johnson CD, Harmsen WS, et al. Colorectal cancer screening with CT colonography, colonoscopy, and double-contrast barium enema examination: prospective assessment of patient perceptions and preferences. Radiology. 2003;227:378-84.

23. Subramanian S, Tangka FKL, Hoover S, Cole-Beebe M, Joseph D, DeGroff A. Comparison of program resources required for colonoscopy and fecal screening: findings from 5 years of the colorectal cancer control program. Prev Chronic Dis. 2019;16:E50.

24. Porter, M. E., \& Kaplan, R. S. How to pay for health care. Harv Bus Rev. 2016 94(7-8), 88-98.

25. Patel K, Presser E, George M, McClellan M. Shifting away from fee-forservice: alternative approaches to payment in gastroenterology. Clin Gastroenterol Hepatol. 2016;14:497-506.

26. Ivanina E, Obe V, Mitra T, et al. Mo1072 New York City Colonoscopy Quality Benchmarking Group (NYC CQBG): screening colonoscopy data on the association between adenoma detection rate and follow-up interval recommendations. Gastroenterology. 2015;148:S-597.

27. John BJ, Irukulla S, Mendall MA, Abulafi AM. Do guidelines improve clinical practice? - a national survey on surveillance colonoscopies. Colorectal Dis. 2010;12:642-5.

28. Piper MS, Maratt JK, Zikmund-Fisher BJ, et al. Patient attitudes toward individualized recommendations to stop low-value colorectal cancer screening. JAMA Netw Open. 2018;1:e185461.

29. Repici A, Aragona G, Cengia G, et al. Low risk of COVID-19 transmission in GI endoscopy. Gut. 2020;69:1925-7.

30. American Society of Gastrointestinal Endoscopy. ASGE gastroenterology professional society guidance on endoscopic procedures during the COVID-19 pandemic. Available at: https://www.asge.org/home/advanced-education-training/covid-19-asge-updates-for-members/gastroenterology-professional-society-guidance-on-endoscopic-procedures-during-the-covid-19-pandemic. Accessed January 21, 2021.

31. Brownlee, S., Korenstein, D. Better understanding the downsides of low value healthcare could reduce harm. BMJ, 2021; 372:n117.

Publisher's Note Springer Nature remains neutral with regard to jurisdictional claims in published maps and institutional affiliations. 